under the Programme for a Next Generation of Vehicles (PNGV), one of the US president's favourite technology programmes.

The administration is assessing the economic impact of any action the United States might take to cut emissions. But results of the analysis, which were due this month, are running late, and Everly Ehrlich, undersecretary of commerce and the official leading the assessment, has just left his post.

Nevertheless, the administration appears happy to announce its plans later rather than sooner, as this will minimize the opportunity for domestic criticism of them to build up before Kyoto. Any proposal for cuts is likely to come under sustained attack from opponents in US industry. Last week, the Business Roundtable, a powerful forum of 200 leading American business leaders, announced a \$1million advertising campaign against such cuts in the run-up to the UN session.

And even if Clinton agrees to mandatory emissions cuts in Kyoto, the political outlook for substantive action on US greenhouse-gas emissions is uncertain, say observers on both sides of the debate. Such measures would be opposed not just by Republicans, who control both houses of the Congress, but by key Democrats as well.

John Dingell (Democrat, Michigan), for example, the senior Democrat on the Commerce Committee in the House of Representatives, is worried that they could hurt car manufacturers in Detroit, and Richard Gephardt (Democrat, Missouri), leader of the House Democrats, may oppose them to help win support among trade union leaders in preparation for his expected bid for the Democrat presidential nomination.

But the administration, prodded by the European states, may agree to emissions cuts in Kyoto and think about implementation afterwards. "Immediate ratification [of a Kyoto agreement] by the Senate is not the key," says Lash, who argues that a strong agreement there will put pressure on the Senate to take the threat of global warming seriously.

It would then be up to Clinton and to $\mathrm{Al}$ Gore, the vice-president and by far the strongest advocate of emission limits in the administration, to win treaty ratification in the Senate and support for enforcement legislation in both houses of Congress.

Gore, who has been keeping a low profile after some political embarrassments over fund-raising earlier this year, has recently been silent on the issue. Environmentalists argue that if he does not continue to take a firm stand on global warming, he will lose credibility in his own bid for the presidency.

But Gore's political handlers may view the matter differently. Like other US politicians, he has little to gain, but much to lose, by demanding economic sacrifice in response to a threat that does not affect the daily lives of most Americans. Colin Macilwain

\section{...as Japan seeks to bridge split on emissions policy}

[TOKYO] A lack of consensus between Japan's powerful Ministry of Trade and Industry (MITI) and its Environment Agency over the future reduction of greenhouse-gas emissions is delaying Japan's preparations for the United Nations (UN) climate change conference, to be held in Kyoto in the first week of December.

Signatories to the UN Framework Convention on Climate Change will be looking to Japan to guide the week's tortuous negotations. But Japan's leadership is by no means guaranteed, as so far the host nation has yet to make up its own mind on legally binding limits to greenhouse gases from 2000.

While European countries, acting jointly through the European Union, have already proposed a 15 per cent reduction in emissions from 1990 levels (see Nature 386, 103; 1997), MITI and Japan's Environment Agency are having difficulty in agreeing on reduction methods and targets. According to officials in Tokyo, MITI is lobbying for a per capita-based proposal, whereas the Environment Agency wants a flat-rate reduction.

In an attempt to avoid mounting international embarrassment, Japan's foreign ministry last December brokered a compromise to allow Japan to put a broad proposal on the table. This consists of a flat-rate reduction in emissions for industrialized countries, and a per capita-based emissions ceiling for developing countries, whose emissions are still rising. This is being viewed by some as close to the ideal compromise during the Kyoto negotiations, where arguments will also centre on the question of emissions reductions for developing countries.

The United States wants to include developing countries in a broad protocol at some stage. But these countries will resist any flatrate reduction as a threat to their industrialization plans. The idea of an emissions ceiling may be an attractive alternative.

But the two ministries are still divided on how, by how much and for how long Japan's own carbon dioxide emissions should be reduced from 2000. MITI appears to be basing its case on the argument that predictions of population growth imply an increase in demand for energy that will make a total reduction impossible.

Rather than revising its energy policy already under severe political strain - MITI is therefore suggesting that per capita rates should be considered. Doubling the number of nuclear power stations in Japan might lead to a reduction in emissions, but it would take time, and recent scandals at the Monju and PNC reactors make this politically difficult.

As the host country for the Kyoto meeting, Japan is expected to lead the negotiations,

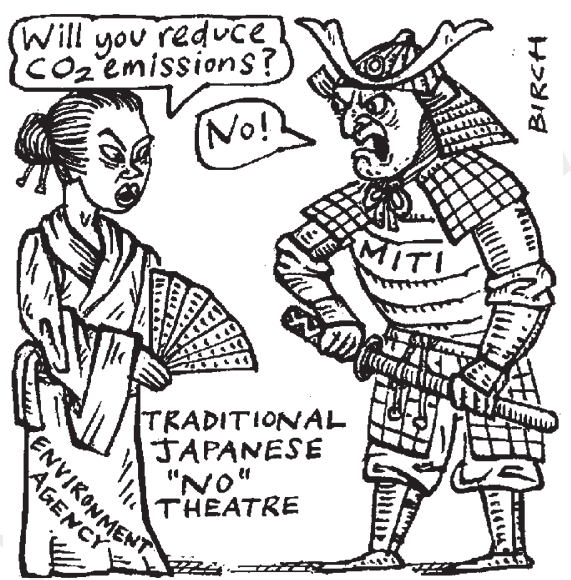

which involve about 150 countries. But the apparent discrepancy between Japan's international position and its internal disagreements has created concern among some foreign observers that this could reduce the chance of a successful outcome of what is likely to be a politically charged conference.

Some internal critics are also keen that, as host country, Japan should not sit on the fence and merely adapt its position to prevailing political forces at the last moment. But Japanese government officials say that they hope to finalize their position before the annual meeting of the Group of Eight (G8) major industrialized nations in Denver, Colorado, later this month.

Environmental topics - including the Kyoto meeting - are due to figure high on the summit's agenda, and Ryutaro Hashimoto, Japan's prime minister, is expected to propose that Japan hosts an international conference on freshwater supplies in developing countries later this year.

Nevertheless, some foreign observers in Tokyo feel that political pressure from overseas will be needed to encourage Japan to make the compromises it needs to decide on carbon dioxide emissions. Some feel it is a decision that may, unusually, have to be taken at cabinet level.

Japan is expected to be severely criticized at Kyoto by nongovernmental organizations for its lack of success in reducing emissions so far. At the 1992 meeting in Rio, Japan and other industrialized nations promised to reduce emission to 1990 levels by 2000 , but on current projections Japan is unlikely to meet this target (see Nature 387, 447; 1997).

In 1995, Japan's carbon dioxide emissions increased by 0.5 per cent to a record 332 million tonnes, an increase of 8.3 per cent on 1990. Many other countries, including the United States, are also unlikely to meet these targets. But a particularly awkward spotlight is expected to fall on the host country's record at the conference.

RichardNathan 